\title{
Budget holding: a step into the unknown
}

\author{
John Bain
}

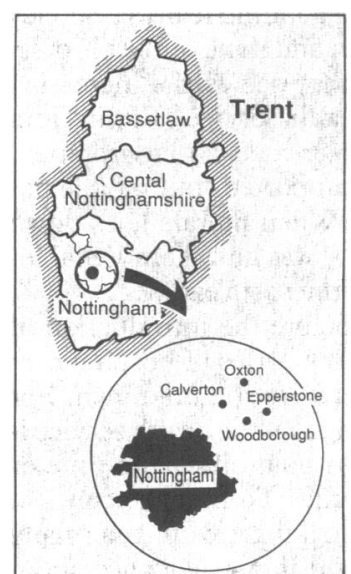

Aldermoor Health Centre, Southampton SO1 6ST John Bain, MD, professor of primary medical care

Correspondence to: Professor J Bain Department of General Practice, Levinson House, Edinburgh EH8 9DX

BMf 1991;302:771-3
Most general practitioners have found the new 1990 general practice contract overwhelming. For many it continues to dominate their working lives, overshadowing the changes to the NHS as a whole that will come on 1 April. This is mainly because the government has decreed a "smooth take off" in the first year, with districts and units agreeing contracts on the basis of existing referral patterns. Perhaps because of this many districts seem not to have involved general practitioners in the business of negotiating contracts, consulting them only in the most general terms. There is, however, one group of general practitioners for whom the changes in 1991 will have a much bigger impact: the practices that will be budget holders. One of these practices is the Calverton practice in Nottinghamshire.

\section{"Proud to be a partner in Calverton"}

The Calverton area is predominantly rural, comprising one large village (Calverton) and three smaller ones (Woodborough, Epperstone, and Oxton). Calverton, with over half the patients, is a semi-industrial village with a declining coal industry as its main base. The other villages are more rural and have tended to attract affluent commuters from Nottingham, which is about $20 \mathrm{~km}$ (12 miles) away.

The practice, which is part dispensing, was formed in 1965 and is based in purpose built premises owned by the partners. The health centre is situated behind the library in the main square of the village and next to the health authority's premises for community based primary care staff. In January 1991 the list size was 9184 and the practice had five partners ranging in age from 35 to 53-Drs Norman Stoddart, Tom Venables, Don Simpson, Louise Maile, Tom O'Dowd-and one trainee assistant, Elizabeth Loughridge. Details of

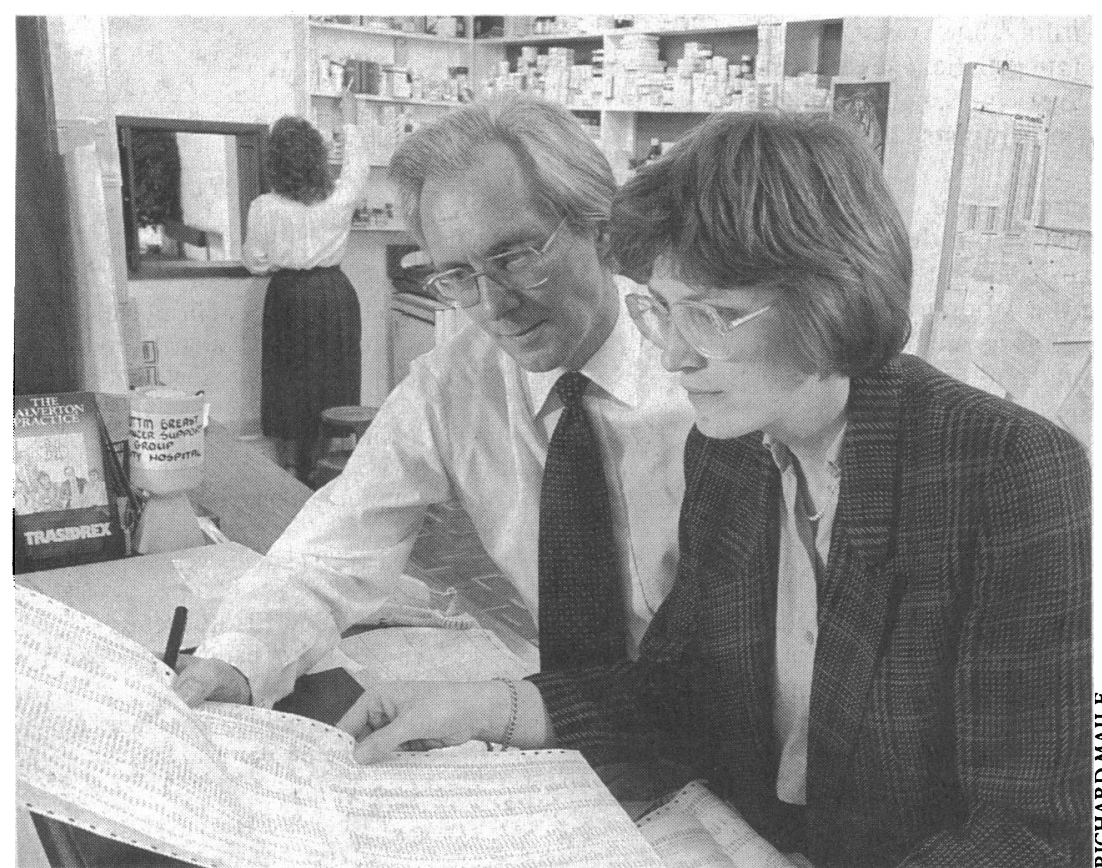

Poring over the paperwork: Drs Norman Stoddart and Louise Maile staffing, organisation and medical services provided are shown in the boxes overleaf.

The partners in Calverton have always considered themselves to be innovative and have been at the forefront of many of the developments in general practice during the past decade. Dr Stoddart has been interested in computer assisted medical records for many years, and a fully operational information system with terminals in each consulting room had been installed well in advance of the publication of the 1989 white paper Working for Patients. The practice has been concerned with postgraduate training since the beginning of the Nottingham vocational training scheme and associated with undergraduate teaching since 1974.

This involvement with undergraduate and postgraduate education had been a stimulus to regular performance review, and over the past 15 years the practice has conducted a series of audit exercises. This spirit of critical inquiry allied to a strong sense of teamwork was summed up by Dr Tom Venables: "If you are a partner in this practice you are proud to say so."

\section{Opportunities within the new contract}

Despite the advantages of good teamwork and a well organised information system, the partners did not welcome the introduction of the new contract in April 1990: it "shifted our innovative potential because we suddenly found ourselves having to do things that we didn't think were important." They found clinical care being eroded by administrative tasks, form filling, and paper work-all of which they saw as chores that interrupted the previous momentum of the practice.

In the midst of coping with these changes in practice organisation the partners also started to explore the opportunities offered by budget holding. It soon became clear to them that the only way to embrace the changes in the health service while maintaining a spirit of innovation that would allow them to develop their practice was to have the freedom to manage their resources. "If we are to have any control over our own destiny [budget holding] appears to be the way forward."

Money is not the motivating force; it is more a question of the partners being able to determine their own priorities for patient care rather than having methods of care imposed from outside. This view has in fact been reinforced by the first year of the general practitioner contract. The partners see this as an imposition, with some aspects (such as health promotion) being inappropriate. A secondary consideration is the extra resources for practice organisation and delivery of care that would not otherwise be available.

\section{Making it happen}

After they had decided to become a budget holding practice the partners took the first step of appointing a practice development manager in September 1990. David Parton has a management background which includes experience in banking, building societies, and insurance companies. $\mathrm{He}$ is having to adjust to the culture of general practice, and his aim is "to move the 


\begin{tabular}{|ll|}
\hline Staffing and organisation \\
List size: & 9184 \\
Premises: & Purpose built health centre \\
Surgeries: & $9-1$ Monday-Friday \\
& $5-6.30$ Monday-Thursday \\
& Saturday morning \\
Partners: & Drs Norman Stoddart, Tom \\
& Venables, Don Simpson, \\
& Louise Maile, Tom O'Dowd \\
Practice development & David Parton \\
manager: & 17 (7.92 full time equivalent \\
Employed staff: & reception and secretarial staff; \\
& $2 \cdot 66$ full time equivalent \\
& nursing staff $)$ \\
Attached staff: & 2 District nurses \\
& 2 Health visitors \\
& 1 Midwife \\
Computer assisted & records with terminals in each \\
consulting room. & \\
& \\
\hline
\end{tabular}

practice towards more professional management." This is not just a question of maximising income but also of introducing methods of personnel management, staff appraisal systems, team learning, policy making, and strategic planning. He thinks that the ethos of the practice will always come from the general practitioners but that they in turn will have to become more aware "of the administrative and financial implications of introducing new services."

Having appointed a manager, the practice also now has the possibility of strengthening its information system and negotiating the best possible arrangements for patients' referral to hospital and use of laboratory services. Despite the fact that the practice has been using computer assisted records for many years, the information collected is primarily about individual patients, and this lack of aggregated data has hampered the negotiating process. There are, for example, no accurate figures about annual consultation rates, and hospital referrals are being estimated on the basis of the last three months of 1990 .

At present the practice refers most of its patients to one of two hospitals in Nottingham-the Queen's Centre and City Hospital - and in the short term it will continue to use these hospitals, though the partners do see that things may change in future. They are officially exploring the opportunity of siting one or two "low tech" outpatient services within their own health centre. These include consultant outpatient sessions in specialties such as dermatology and rheumatology along with sessions by physiotherapists and chiropodists.

Laboratory investigations are a clear area where fundholders can "play the market," but the Calverton practice has no immediate plans to do so; for the time being it will continue to use the laboratories it uses now, but the partners are "exploring the options" for the future. One of these options is to use the practice budget to develop some in house laboratory servicesones that do not depend on expensive capital equipment.

When I visited the practice, in January, the support staff were largely consumed by the demands of providing care and had not played a central part in the decision making about budget holding. Nevertheless, both clerical and nursing staff were enthusiastic about their extended roles in providing primary care and thought that "if budget holding results in shorter waiting times for patients attending hospital then it must be a good thing." The dispenser, for example, foresaw the creation of a drug formulary which "could lead to money being saved and ploughed back into the practice." Clearly, teamwork in the practice is at a level that can cope with new ideas, and it is encouraging to observe the extent to which support staff trust the doctors to investigate new methods of providing care.

\section{Problems}

Despite the underlying desire to be pioneers all the partners recognise the risk in budget holding, especially at a time when the parallel commitment of working within the new contract is sapping their energy. "We all feel stressed and have great difficulty pacing ourselves." There is a genuine fear that money will become the driving force, and none of the partners are comfortable with what they see as the increasing commercialisation of the health service. Enthusiasm for innovation has probably created an environment within which risk taking is supported, but morale has been difficult to maintain. "When morale goes down then vision becomes blurred," was how Tom Venables described the experiences of the past year.

In January, two months before the introduction of the budget holding system, the prices of hospital care and laboratory investigations were still unknown. For David Parton it is "astonishing that the health service is moving into new territory without either the time or the information to plan ahead." To him the contrast with private industry is striking, with too many proposals for change based on flimsy evidence about whether they will lead to improvements in patient care. $\mathrm{He}$ is having to negotiate with health authority managers equally in the dark about the cost of hospital and laboratory services. There appears to be little agreement within either the family health services authority or the local hospitals about how prices for patient care should be estimated and this is leading to frustration and uncertainty within the practice.

Norman Stoddart, the senior partner, is also concerned that there is no guarantee that the costs of upgrading the computer system will be underwritten. In addition the hospital based computer systems cannot link directly with the practice computer. Diagnostic coding systems in hospitals and general practice do not match, and piles of computer print outs are being exchanged that bear little relation to each other. "Thriving on chaos" was Tom O'Dowd's comment, but there are times when the doctors doubt their decision to opt for fundholding. "We are in a situation where no one seems capable of unravelling the complexities of negotiating the costs of patient care."

\section{Medical services}

$\begin{array}{ll}\text { List size: } & 9184 \\ \text { Children }<5 \text { years: } & 5 \cdot 9 \% \\ \text { Patients }>75 \text { years: } & 5 \cdot 1 \% \\ \text { Clinics: } & \begin{array}{c}\text { Well man, well woman, child } \\ \text { surveillance; antenatal and } \\ \text { postnatal clinics held within }\end{array} \\ & \text { surgery consultations } \\ \text { Health promotion: } & \begin{array}{c}\text { Mainly opportunistic } \\ \text { Cervical cytology }>80 \%\end{array} \\ \text { Contract targets: } & \begin{array}{l}\text { Immunisation (children) }>90 \% \\ \text { Estimated hospital }\end{array} \\ \text { referral rate: } & 142 / 1000 \text { patients/year } \\ \text { Practice prescribing } & \begin{array}{c}\text { Overall costs } \\ \text { (PACT data): }\end{array} \\ & 6 \% \text { below FHSA average } \\ & 14 \% \text { below national average } \\ & \text { Items per prescription } \\ & 2 \% \text { below FHSA average } \\ & 2 \% \text { below national average } \\ & \text { Cost per item } \\ & 4 \% \text { below FHSA average } \\ & 12 \% \text { below national average }\end{array}$


The staffing implications of the new system are still unknown, but it is already apparent that the practice manager cannot shoulder all the administrative tasks on his own. With no history of budget holding in NHS general practice no one has any experience of how it might work in practice. Moreover, as one of only four practices in the Nottingham area which have decided to become fundholders the practice feels isolated and exposed. Standing "out of line" has not been easy.

Running through all the discussions about stepping into the unknown has been the problem of time management. The partners are asking serious questions about the price that has to be paid in terms of attending frequent meetings about practice organisation. Bialogue about clinical care had been reduced and "the enjoyment of being a GP is no longer so apparent." On the other hand, however, the need to meet regularly has focused attention on how best to cope with the many changes and gain clarity about the future.

\section{Future direction}

The monthly business meetings may have taken their toll in time, but several important ideas have emerged from them which will help shape the future of the practice. Among these is a practice business plan based on a mission statement, which defines the core purpose of the practice and its key aims. The agreed aims are:

(1) To provide the best possible primary health care for patients registering with the practice through personal and continuing family care.

(2) To expand and develop the range of in house health care services offered to patients, building on the strength of the practice and staff.

(3) To take control of the provision of health care services in the practice area and to encourage the wider improvement of health care through training and research.

(4) To develop a healthy, mutually supportive environment in which the practice may prosper.

Working on these aims has brought the partners together and is helping them towards a shared vision of those values that are central to the day to day work of the practice. But merely writing a mission statement will not be enough if the expected benefits of budget holding do not come alive.

One of these benefits is the freedom for the practice to decide its own priorities in patient care and to invest in supporting the needs of specific groups of patients. Yet the views of patients in the practice have not been seriously canvassed.

As well as sharing vision the partners have also explicitly had to share the tasks of practice management. Different partners are each responsible for accomplishing the practice's current priorities: producing a drug formulary, publishing a practice report, organising the continuing education of nurses, and reviewing the information system.
In Norman Stoddart's view, "These efforts will ultimately lead to a slicker primary care team with a much clearer definition of roles within the practice." For David Parton, the practice manager, his task is "to get the doctors involved at a level which is strategic rather than merely adopting patch up policies." Tom O'Dowd, the most recent addition to the partnership, still thinks that "the opportunities available could lead to clashes over professional values, but the experiences gained in tackling unexplored areas should cement relationships within the group and provide guidance for other practices."

An unknown outcome of budget holding is the inevitable change which will occur in the relationships between general practitioners and consultants. Some consultants are certainly taking a greater interest in the practice and its needs now that they know it will be a fundholder. Health authority and family health service authority managers are also paying the practice a lot of attention, and the partners expect to be under scrutiny for some time.

In January the partners still did not have their budget and feared that they would have little time for manoeuvre with the starting date of 1 April only weeks away. They found it hard to negotiate services when the financial situation was still unclear. Now they have a budget (smaller than they expected), but they are still troubled by mixed messages about costs. No one seems able to give them accurate costings for the services they want to buy.

\section{Conclusions}

My overriding impression of the Calverton practice is that the partners (and staff) have a strong sense of ownership of the values and standards that have grown up over the years. The location does not present any major problems in reorganising care and the support systems - staffing and computerised records-are well established. The general practitioners' sense of direction has been jolted by the new contract, and this is continuing to cause stress because of the increased administrative workload, much of it fruitless in terms of patient care.

During the past decade the practice has created an environment where new ideas are welcomed and audit is a regular feature. Holding a budget is seen as the only way of maintaining that environment and of liberating the practice from the rigidities of the general practitioner contract. The partners and staff are united in their efforts to overcome current difficulties by setting out plans for the future, but those in management positions outside the practice will also need to be conversant with the practice's aims if budget holding is not to produce conflict. Probably the most important requirement, however, in the Calverton partners' attempts to obtain job satisfaction will be the energy to maintain their shared vision.

I thank the partners and staff of Calverton practice, who gave up so much of their valuable time for these discussions.

\section{ANY QUESTIONS}

Does the chronic discharge that commonly follows fenestration operation exacerbate the hearing loss of otosclerosis?

The fenestration operation was popular before stapedectomy - that is, before 1965. Sensorineural hearing loss gradually develops in most patients with otosclerosis treated by fenestration. This is caused by presbycusis, otosclerosis affecting the cochlea, and chronic suppura- tion in the cavity resulting from fenestration. It is a well recognised feature that gradual sensorineural hearing loss develops in patients with a chronically discharging mastoid cavity. Whether this sensorineural deafness is due to the presence of infection so close to the inner ear or to repeated episodes of acute labyrinthitis is not clear. - MAURICE HAWTHORNE, consultant otolaryngologist, Middlesbrough 